\title{
Food Ingestion Standards for Nuclear Emergency Exposure Situations
}

\author{
Dong-Kwon Keum*, Hyojoon Jeong, In Jun, Kwang-Muk Lim, Yong-Ho Choi, Won-Tae Hwang \\ Korea Atomic Energy Research Institute, Daejeon, Korea
}

\section{Technical Paper}

Received May 25, 2017

Revision July 12, 2017

Accepted August 3, 2017

Corresponding author:

Dong-Kwon Keum

Korea Atomic Energy Research Institute, 989-111 Daedeokdaero, Yuseong-gu,

Daejeon 34057, Korea

Tel: $+82-42-868-2058$

Fax: +82-42-868-8606

E-mail: dkkeum@kaeri.re.kr

This is an Open-Access article distributed under the terms of the Creative Commons Attribution NonCommercial License (http://creativecommons.org/ licenses/by-nc/4.0) which permits unrestricted noncommercial use, distribution, and reproduction in any medium, provided the original work is properly cited.

Copyright $\odot$ 2017 The Korean Association for Radiation Protection

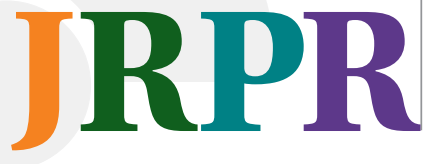

Background: This study presents food ingestion standards for radioactivity that can be applied in nuclear emergency exposure situations, and discusses the validity of the current domestic standards.

Materials and Methods: This study derived food ingestion standards for radiocesium and radioiodine using domestic food intake rates and intervention levels, which serve as a basis for determining the necessity of public protective actions, and then compared them with the existing guidelines. Operational intervention levels were also derived using domestic food intake rates, and were compared with those of the International Atomic Energy Agency.

Results and Discussion: The derived activity concentrations for food ingestion standards of radiocesium for infants were higher than those in the Act on Physical Protection and Radiological Emergency (APPRE) for all food categories, while for adults, the derived activity concentrations for drinking water and milk appeared to be slightly lower. The derived activity concentrations for vegetables, fruits, and grains were greater than those in the guidelines of the APPRE, while the derived activity concentrations for meat and seafood were similar to those in the APPRE. The derived activity concentrations for radioiodine were greater than both domestic and global standards. The calculated operational intervention levels (OILs) based on domestic food intake rates were greater than the IAEA's default OIL6 values for most radionuclides, except for a few $\alpha$-radionuclides.

Conclusion: The current domestic guidelines turned out to be conservative overall, compared to the present results that were calculated using domestic food intake rates. It is recommended that the domestic guidelines should be revised and complemented transparently through an indepth review by stakeholders on a solid scientific basis.

Keywords: Nuclear accident, Domestic food intake rate, Food ingestion standard of radioactivity, Operational intervention levels

\section{Introduction}

In the event of a nuclear accident, public protective actions are one of the essential responses for ensuring public safety. Detailed guidelines according to the progression of the accident should be developed in advance, in the preparedness stage, in order for public protective actions to be implemented effectively in a real accident situation.

The International Commission on Radiological Protection (ICRP) proposed reference levels for protecting people from ionizing radiation according to the exposure situation $[1,2]$. The proposed reference levels for the management of emergency exposure fall into the range of $20-100 \mathrm{mSv} \cdot \mathrm{y}^{-1}$, and an action level should be preferably se- 
lected in this band for accidental situations. For instance, for the management of the Fukushima accident, the government of Japan applied a reference level of $20 \mathrm{mSv} \cdot \mathrm{y}^{-1}$, which is the lower limit of the reference band for emergency exposure situations recommended by the ICRP. This means that the Japanese government managed the individual exposure from all exposure pathways, including ingestion, within 20 $\mathrm{mSv} \cdot \mathrm{y}^{-1}$ during the initial emergency period.

Restrictions on the consumption and distribution of food in the contaminated area after a nuclear accident are an important public protective action. In the case of the Chernobyl disaster in 1986, the Soviet government did not take appropriate protective actions for local residents in the initial phase of the accident, meaning that many infants and children consumed milk contaminated with radioiodine, which caused thousands of people to develop thyroid cancer. This case clearly demonstrates the importance of food restrictions after a nuclear accident [3].

The International Atomic Energy Agency (IAEA) proposed general safety guidelines to be used for protecting people after a nuclear accident, and advised member states to adopt these recommendations considering the environmental factors of each country [4]. Accordingly, the Republic of Korea has established its own guidelines for public protective actions in case of a nuclear accident, including food ingestion standards of radioactivity in the Act on Physical Protection and Radiological Emergency (APPRE) (Article 15-1, attached Table 4).

Additionally, the Ministry of Food and Drug Safety (MFDS) proposed food ingestion guidelines for radioiodine and radiocesium (http://www.mfds.go.kr). However, the guidelines of the APPRE and MFDS are not aligned with each other, and both are inconsistent with those of the Codex Alimentarius Commission (CAC) of the World Health Organization (WHO) [5]. The APPRE proposes guidelines in terms of 5 categories of radionuclides and 4 categories of food, while MFDS uses 2 and 4 categories and the CAC utilizes 4 and 3 categories, respectively. In general, radionuclides are classified by the radiation risk that they pose when ingested from food. The guidelines of the APPRE and CAC contain the following major differences: 1) the APPRE classifies ${ }^{103} \mathrm{Ru}$ and ${ }^{106} \mathrm{Ru}$ in the same radionuclide group, while CAC classifies ${ }^{103} \mathrm{Ru}$ in a higher risk group; 2 ) the APPRE classifies ${ }^{235} \mathrm{U}$ and ${ }^{238} \mathrm{U}$ in a separate radionuclide group with strengthened criteria, while CAC classifies ${ }^{235} \mathrm{U}$ as having the same risk as ${ }^{131} \mathrm{I}$ without considering ${ }^{238} \mathrm{U}$; 3 ) the APPRE does not give criteria for ${ }^{14} \mathrm{C},{ }^{99} \mathrm{Tc},{ }^{192} \mathrm{Ir},{ }^{35} \mathrm{~S}$, and ${ }^{60} \mathrm{Co}$, which are included in the CAC guidelines.

Individual countries have their own food ingestion guidelines to be used in emergencies, but the guidelines are different [6]. This is owing to the different dietary customs and practices of each country, including differences in the types and amount of food consumed. It is therefore necessary to set up nation-specific guidelines that consider domestic dietary characteristics, rather than following a general global standard.

This study focuses on the methodology of determining food ingestion standards of radioactivity for the protection of people in nuclear emergency situations, and discusses the food ingestion guidelines for radiocesium and radioiodine by comparing the present results calculated using the domestic food intake rate with the current APPRE and MFDS guidelines. Furthermore, this study proposes derived operational intervention levels (OILs) calculated using domestic food consumption rates, and presents an investigation of their validity through a comparison with those of IAEA.

\section{Materials and Methods}

Protecting people through restricting food ingestion should be justified on radiation protection principles; that is, the benefits of the intervention must outweigh the loss. Restrictions on food consumption would be unnecessary if the activity concentration of food is so low that it would not be likely to have any harmful effects on people's health. In such a case, the expected cost of replacing contaminated food with clean food may outweigh the benefits of preventing possible harmful effects on public health. There are no absolute guidelines for supporting whether an intervention is appropriate because individuals may perceive radiation risks differently even with the same level of contamination. Thus, intervention levels should be derived reasonably based on scientific facts and within the reference guidelines that are supported by a global consensus.

Once the intervention levels are set up, the derived radioactivity concentration for a restriction on food consumption can be calculated as:

$$
R C I L_{j k}=\frac{I L / G}{F W_{j k} \sum C F_{i} f_{i}\left(1-e^{-\lambda_{i} T}\right) / \lambda_{i}}
$$

where,

$R C I L_{j k}$ : Derived activity concentration of food by age ( $\mathrm{j}$ ) 
and food $(\mathrm{k})\left(\mathrm{Bq} \cdot \mathrm{kg}^{-1}\right)$

IL: Intervention level $\left(\mathrm{mSv} \cdot \mathrm{y}^{1}\right)$

$G$ : Number of foods

$F$ : Market dilution factor of foodstuffs

$W_{j k}$ : Average daily food intake by age (j) and food (k) $\left(\mathrm{kg} \cdot \mathrm{d}^{-1}\right)$

$C F_{i}$ : Ingestion dose coefficient of radionuclide (i) $\left(\mathrm{mSv} \cdot \mathrm{Bq}^{-1}\right)$

$T$ : Time for food consumption per annum ( $\mathrm{T}=365$ days $)$

$f_{i}$ : Radioactivity level of coexisting radionuclide i relative to that of the index radionuclide

$\lambda_{i}$ : Radioactive decay constant of radionuclide (i) $\left(\mathrm{d}^{-1}\right)$

For food regulation in emergency exposure situations, the ICRP recommended a band of effective doses between 5 and $50 \mathrm{mSv} \cdot \mathrm{y}^{-1}$, and equivalent doses of 50 and $500 \mathrm{mSv} \cdot \mathrm{y}^{-1}$ to any selectively exposed organ or tissue, respectively, in its Publication 40 [7] in 1984. The WHO proposed an effective dose of $5 \mathrm{mSv} \cdot \mathrm{y}^{-1}$ and an equivalent dose to the thyroid of $50 \mathrm{mSv} \cdot \mathrm{y}^{-1}$ [8]. The intervention level of the WHO corresponds to the lower limit of the ICRP bands. In 1992, the ICRP suggested in its Publication 63 [9] that an effective dose of $10 \mathrm{mSv} \cdot \mathrm{y}^{-1}$ for any single foodstuff would almost always be justified. The corresponding concentration levels of radionuclides are $1,000-10,000 \mathrm{~Bq} \cdot \mathrm{kg}^{-1}$ for $\beta$ and $\gamma$ radionuclides, and $10-100$ $\mathrm{Bq} \cdot \mathrm{kg}^{-1}$ for $\alpha$ nuclides. The level of $1,000 \mathrm{~Bq} \cdot \mathrm{kg}^{-1}$, the lower limit for $\beta$ and $\gamma$ radionuclides, is equivalent to $5.5 \mathrm{mSv} \cdot \mathrm{y}^{-1}$ when calculated using the global average annual food intake (not including drinking water) of $550 \mathrm{~kg}$ and the effective dose conversion factor of $1 \times 10^{-5} \mathrm{mSv} \cdot \mathrm{Bq}^{-1}$ for adults. The same dose is approximately obtained for $10 \mathrm{~Bq} \cdot \mathrm{kg}^{-1}$, the lower limit for $\alpha$ radionuclides, when using the effective dose conversion factor of $1 \times 10^{-3} \mathrm{mSv} \cdot \mathrm{Bq}^{-1}$. Considering the above international intervention levels for food regulations, in the present study, an effective dose of $5 \mathrm{mSv} \cdot \mathrm{y}^{-1}$ for the ingestion of radiocesium and an equivalent dose to the thyroid of 50 $\mathrm{mSv} \cdot \mathrm{y}^{1}$ for the ingestion of radioiodine were selected as the reference intervention levels to derive domestic food ingestion guidelines for emergency exposure situations.

The number of foods $(G)$ can vary according to the radionuclide, as foods may not be contaminated practically by certain radionuclides due to their short half-life. A guideline for a single food would be so simple that it would be likely to facilitate communication between stakeholders. However, at the same time, guidelines for a single food are exposed to uncertainty regarding the determination of the representative activity concentration of food, and can lead to the risk of overexposure from foods that are consumed in large quanti- ties. Moreover, such guidelines could result in excessive measures, such as restricting the consumption of other foods with low-level activity that may be safe, even when only a small portion of food is highly contaminated with radioactivity. On the other hand, if all kinds of food consumed are considered independently in guidelines, the guidelines would be too complex to be applied, and the derived activity concentrations can be biased by applying an identical effective dose $(I L / G)$ to all foods, as well as by uncertainty in the consumption rate of each food. Therefore, it is reasonable to group foods by similar characteristics.

In this study, 5 food groups (drinking water, milk, vegetable/fruits, grains, and meat/seafood) were considered for both radiocesium and radioiodine in order to maintain consistency with the APPRE guidelines. Then, the intervention level for each foodstuff was applied, using an effective dose of $1 \mathrm{mSv} \cdot \mathrm{y}^{-1}$ for radiocesium and an equivalent dose to the thyroid of $10 \mathrm{mSv} \cdot \mathrm{y}^{-1}$ for radioiodine. For reference, it is noted that the Japanese guidelines consist of 5 food categories for radiocesium and 4 for radioiodine [10].

There are no standardized domestic food ingestion rates for radiation ingestion dose calculations. In the present study, the food intake rates presented by the Korea Institute of Nuclear Safety (KINS) [11], which were obtained from domestic nutrition studies to be used for ingestion dose assessments for regulatory purposes, were applied. Processed food was not considered in the calculations under the assumption that the raw material would not be contaminated with radionuclides. For planned exposures, ICRP Publication 101 [12] recommends the use of 95th percentile values of the food consumption rate for a conservative assessment, but in an emergency exposure situation, using the mean food consumption rate is logical to prevent excessive protective actions, and to consider average individuals who receive mean-level exposure.

The ICRP advises the use of 3 age ingestion dose coefficients, for 1-year old infants, 10-year-old children, and adults, but this study applied the dose coefficient for 3-month old infants instead of 1-year old infants for a conservative calculation.

In the study, the market dilution factor of food $(F)$ was set to 1 for radioiodine and 0.5 for radiocesium, which were taken from a Japanese study [10], due to the absence of Korean data. The WHO applied a market dilution factor of 0.1, which means that $10 \%$ of food in the market would be contaminated with radioactivity. Thus, the present study applied a more 
Table 1. The Input Data Used in the Calculation of the Food Intake Restriction Levels

\begin{tabular}{|c|c|c|c|c|c|c|}
\hline \multirow{2}{*}{ Group } & \multirow{2}{*}{ Radionuclide } & \multirow{2}{*}{ Decay constant $\left(\mathrm{d}^{-1}\right)$} & \multirow{2}{*}{$\begin{array}{l}\text { Ratio of coexisting } \\
\text { radionuclides, } f_{i}\end{array}$} & \multicolumn{3}{|c|}{ Ingestion dose coefficient ${ }^{\star}, \mathrm{mSv} \cdot \mathrm{Bq}^{-1}$} \\
\hline & & & & 3 months & 10 years & Adult \\
\hline \multirow[t]{6}{*}{ lodine } & ${ }^{131} \mid$ & $8.62 \times 10^{-2}$ & 1.0 & $3.7 \times 10^{-3}$ & $1.0 \times 10^{-3}$ & $4.3 \times 10^{-4}$ \\
\hline & 132 & 7.232 & 1.3617 & $4.0 \times 10^{-5}$ & $8.3 \times 10^{-6}$ & $3.4 \times 10^{-6}$ \\
\hline & 133 & $7.998 \times 10^{-1}$ & 1.4255 & $9.6 \times 10^{-4}$ & $2.7 \times 10^{-4}$ & $8.2 \times 10^{-5}$ \\
\hline & ${ }^{134} \mid$ & 18.97 & 0.0006 & $6.3 \times 10^{-6}$ & $1.3 \times 10^{-6}$ & $5.4 \times 10^{-7}$ \\
\hline & 135 & 2.517 & 0.5532 & $1.9 \times 10^{-4}$ & $3.9 \times 10^{-5}$ & $1.6 \times 10^{-5}$ \\
\hline & ${ }^{132} \mathrm{Te}$ & $2.127 \times 10^{-1}$ & 1.3191 & $6.5 \times 10^{-4}$ & $7.5 \times 10^{-5}$ & $3.1 \times 10^{-5}$ \\
\hline \multirow[t]{4}{*}{ Cesium } & ${ }^{89} \mathrm{Sr}$ & $1.373 \times 10^{-2}$ & 0.28732 & $3.6 \times 10^{-5}$ & $8.9 \times 10^{-6}$ & $2.6 \times 10^{-6}$ \\
\hline & ${ }^{90} \mathrm{Sr}$ & $6.521 \times 10^{-5}$ & 0.04555 & $1.23 \times 10^{-4}$ & $4.7 \times 10^{-5}$ & $2.8 \times 10^{-5}$ \\
\hline & ${ }^{134} \mathrm{Cs}$ & $9.210 \times 10^{-4}$ & 0.54455 & $2.6 \times 10^{-5}$ & $1.3 \times 10^{-5}$ & $1.9 \times 10^{-5}$ \\
\hline & ${ }^{137} \mathrm{Cs}$ & $6.330 \times 10^{-5}$ & 0.45545 & $2.1 \times 10^{-5}$ & $9.7 \times 10^{-6}$ & $1.4 \times 10^{-5}$ \\
\hline
\end{tabular}

*The ingestion dose coefficients for iodine are that for the thyroid, which were taken from the ICRP Database of Dose Coefficient: Workers and Members of the Public Version 3.0, 2011 (http://www.icrp.org).

conservative approach than that of the WHO. It should be noted that the combination of an $F$ of 1 with an intervention level of $10 \mathrm{mSv} \cdot \mathrm{y}^{-1}$ produces the same derived activity concentration for the guidelines as the combination of an $F$ of 0.1 with an intervention level of $1 \mathrm{mSv} \cdot \mathrm{y}^{-1}$.

By using the ratio of the radioactivity of coexisting radionuclides relative to an index radionuclide $\left({ }^{131} \mathrm{I}\right.$ and $\left.{ }^{137+134} \mathrm{Cs}\right)$ in food $(f)$, the contribution of coexisting radionuclides to the committed dose can implicitly be considered in the derived activity concentration of the index radionuclide. In this study, $f$ was deduced from 2 assumptions: 1 ) the ratio of the radioactivity concentration of ${ }^{90} \mathrm{Sr}$ to ${ }^{137} \mathrm{Cs}$ is $1: 10$, and 2) the ratio of radioactivity of ${ }^{89} \mathrm{Sr}$ to ${ }^{90} \mathrm{Sr}$ (6.308) and the ratio of radioactivity of ${ }^{137} \mathrm{Cs}$ to ${ }^{134} \mathrm{Cs}(0.836)$ are equal to the corresponding ratios inside the reactor at 0.5 days after shutdown of the pressure water reactor (PWR), where fuel with an initial concentration of $3 \%$ is burned at $30 \mathrm{GWd} \cdot \operatorname{ton}^{-1}[10]$.

\section{Results and Discussion}

\section{Calculation results}

The input data used in the calculation are summarized in Table 1 and 2, and the calculated food ingestion guidelines by age group are shown in Table 3 . The lowest values for each radionuclide and food group are highlighted in bold, and these can be used as index values for guidelines.

The lowest activity concentrations for radiocesium calculated using the domestic food consumption rates were 348, $905,758,968$, and 2,003 Bq. $\mathrm{kg}^{-1}$ for drinking water, milk, vegetables/fruits, grains, and meat/seafood, respectively. Of these values, the lowest value, for drinking water (348 $\left.\mathrm{Bq} \cdot \mathrm{kg}^{-1}\right)$, can be proposed as an index value for a representa-
Table 2. Domestic Daily Food Intake Rates $\left(\mathrm{kg} \cdot \mathrm{d}^{-1}\right)$

\begin{tabular}{llccl}
\hline Food & & 1 year & 10 years & Adults \\
\hline Group 1 & Drinking water & 0.51 & 0.85 & 1.0 \\
Group 2 & Milk & 0.22 & 0.2 & 0.06 \\
Group 3 & Vegetables & 0.05 & 0.22 & 0.37 \\
& Fruit & 0.063 & 0.091 & 0.09 \\
Group 4 & Grain & 0.126 & 0.32 & 0.36 \\
Group 5 & Seafood & 0.016 & 0.037 & 0.074 \\
& Meat & 0.029 & 0.115 & 0.1 \\
& Processed food & 0.163 & 0.175 & 0.27 \\
Total & & 1.177 & 2.008 & 2.324 \\
\hline
\end{tabular}

tive guideline for all kinds of food since it satisfies the criteria of other foods as well. The proposed index value is slightly lower than the MDFS guideline for adults of $370 \mathrm{~Bq} \cdot \mathrm{kg}^{-1}$, but about 3.5 times higher than the APPRE guideline for infants of $100 \mathrm{~Bq} \cdot \mathrm{kg}^{-1}$. In comparison with the APPRE guidelines, it can be shown that the present results for drinking water and milk for adults were approximately 1.7 times higher, while for vegetable/fruits for adults, our results were $25 \%$ lower than those contained in the APPRE guidelines. The index value for grains was estimated to be $50 \%$ lower than the value in the APPRE guidelines, whereas the index value for meat/ seafood appeared to be similar. In short, the current APPRE guidelines apply very conservative criteria for infants, and rather conservative criteria for drinking water and milk for adults, compared to the index values in this study calculated using the domestic food intake rate. However, a comparison between the WHO and the APPRE guidelines shows that the APPRE guidelines are more conservative, except for meat/ seafood. This is ascribed to the application of different intervention levels and food consumption rates between the APPRE and WHO. 
Table 3. Calculated Levels and Comparison with Other Guideline Levels

\begin{tabular}{|c|c|c|c|c|c|c|c|c|}
\hline \multirow{2}{*}{ Radionuclide } & \multirow{2}{*}{ Food } & \multicolumn{3}{|c|}{ Calculated level, Bq· $\mathrm{kg}^{-1}$} & \multicolumn{2}{|c|}{ APPRE* (Korea) $^{*}$} & \multicolumn{2}{|c|}{$\mathrm{CAC}^{\dagger}(\mathrm{WHO} / \mathrm{FAO})$} \\
\hline & & Infants & 10 years & Adults & Infants & Adults & Infants & Adults \\
\hline \multirow[t]{7}{*}{${ }^{134+137} \mathrm{Cs}$} & & \multicolumn{3}{|c|}{ IL: effective dose of $5 \mathrm{mSv}$} & 100 & 200 & 1,000 & 1,000 \\
\hline & Drinking water & 390 & 551 & 348 & & & & \\
\hline & Milk & 905 & 2,341 & 5,808 & 100 & 200 & 1,000 & 1,000 \\
\hline & Veg., fruit & 1,810 & 1,510 & 758 & 100 & 1,000 & 1,000 & 1,000 \\
\hline & Grains & 1,580 & 1,463 & 968 & 100 & 2,000 & 1,000 & 1,000 \\
\hline & Meat, seafood & 4,424 & 3,080 & 2,003 & 100 & 2,000 & 1,000 & 1,000 \\
\hline & Single food & 985 & 1,278 & 848 & & & & \\
\hline \multirow[t]{7}{*}{${ }^{131}$} & & \multicolumn{3}{|c|}{ IL: thyroid dose of $50 \mathrm{mSv}$ (effective dose of $5 \mathrm{mSv}$ ) } & 10 & 100 & 100 & 100 \\
\hline & Drinking water & 403 (792) & $937(1,748)$ & $1,876(3,488)$ & & & & \\
\hline & Milk & $933(1,836)$ & $3,982(7,429)$ & $31,267(58,137)$ & 10 & 100 & 100 & 100 \\
\hline & Veg., fruit & $1,866(3,672)$ & $2,569(4,793)$ & $4,078(7,583)$ & 10 & 500 & 100 & 100 \\
\hline & Grains & $1,629(3,206)$ & $2,489(4,643)$ & $5,211(9,689)$ & 10 & 1,000 & 100 & 100 \\
\hline & Meat, seafood & $4.562(8,976)$ & $5,240(9,774)$ & $10.782(20,047)$ & 10 & 1,000 & 100 & 100 \\
\hline & Single food & 1,015 & 2,174 & 4,567 & & & & \\
\hline
\end{tabular}

*Act on Physical Protection and Radiological Emergency of Korea (Article15-1, attached Table 4).

${ }^{\dagger}$ In the derivation of the Codex Alimentarius Commission (CAC) guidelines, $550 \mathrm{~kg}$ and $200 \mathrm{~kg}$ of food is assumed to be consumed by an adult and infant in a year, respectively, and the generic intervention level is $1 \mathrm{mSv}$ for individuals [5].

IL, intervention level; WHO, World Health Organization; FAO, Food and Agriculture Organization of the United Nations.

For radioiodine, the lowest activity concentration was 403 $\mathrm{Bq} \cdot \mathrm{kg}^{-1}$ for drinking water for infants, which is 4 to 10 times higher than the existing levels of domestic and international organizations. The present index levels for radioiodine were higher for all foods than those in the APPRE guidelines, indicating that the current Korean and global guidelines seem to be very conservative. The WHO presents very strict guidelines for radioiodine. The purpose of this seems to control carefully the consumption of food contaminated with radioactive iodine in the initial phase of a nuclear accident, based on the lessons learned from the Chernobyl accident.

\section{The effect of the input data on the calculation results}

1) The effect of the market dilution factor of foodstuffs $(F)$

In general, the value of $F$ decreases with time owing to restrictions on food consumption and the withdrawal of contaminated food from the market. To investigate the temporal effect of the market dilution factor, the activity concentration of foodstuffs was calculated with $\mathrm{F}$ as a function of time ( $F=e^{-0.0063 t}, F=0.1$ at $t=365$ ), and the results were compared with those calculated using a constant value of $F$, as shown in Figure 1. It was found that the calculated activity concentration increased by $21 \%$ for adults and $12 \%$ for infants for radiocesium, and by $7 \%$ for both adults and infants for radioiodine, compared to the assumption of a constant value ( $F=1$ for radioiodine, $F=0.5$ for radiocesium). These results suggest that the present approach using a constant value of $F$ may be more conservative than using time-variant $F$. The committed dose from radioiodine almost reaches its annual limit (equivalent dose to the thyroid of $10 \mathrm{mSv}$ ) within the first 40 days after the accident. In other words, radioiodine no longer contributes to radiation risk after 40 days due to its short half-life. Thus, the assumption of $F=1$ for radioiodine is reasonable. In contrast, radiocesium has a long half-life, meaning that its committed dose peaks at $1 \mathrm{mSv}$ at 365 days. It would therefore be acceptable to assume $F$ of 0.5 , considering the decrease of $F$ with time.

\section{2) The effect of coexisting radionuclides}

Coexisting radionuclides were introduced into the model to reflect their impact on the activity concentration of index radionuclides. When coexisting radionuclides were not considered, the derived activity concentration for radioiodine increased by $7 \%$ and $13 \%$ for adults and infants, respectively, and the derived activity concentration for radiocesium increased by $4 \%$ and $28 \%$, respectively, compared with when coexisting radionuclides were considered (Figure 2). As a result, the derived activity concentration for index radionuclides became lower when accounting for the additional contributions of coexisting radionuclides to the committed dose.

3) The effect of the number of foods $(G)$

The difference in the index value between a single food and multiple foods was investigated. A single food $(G=1)$ 

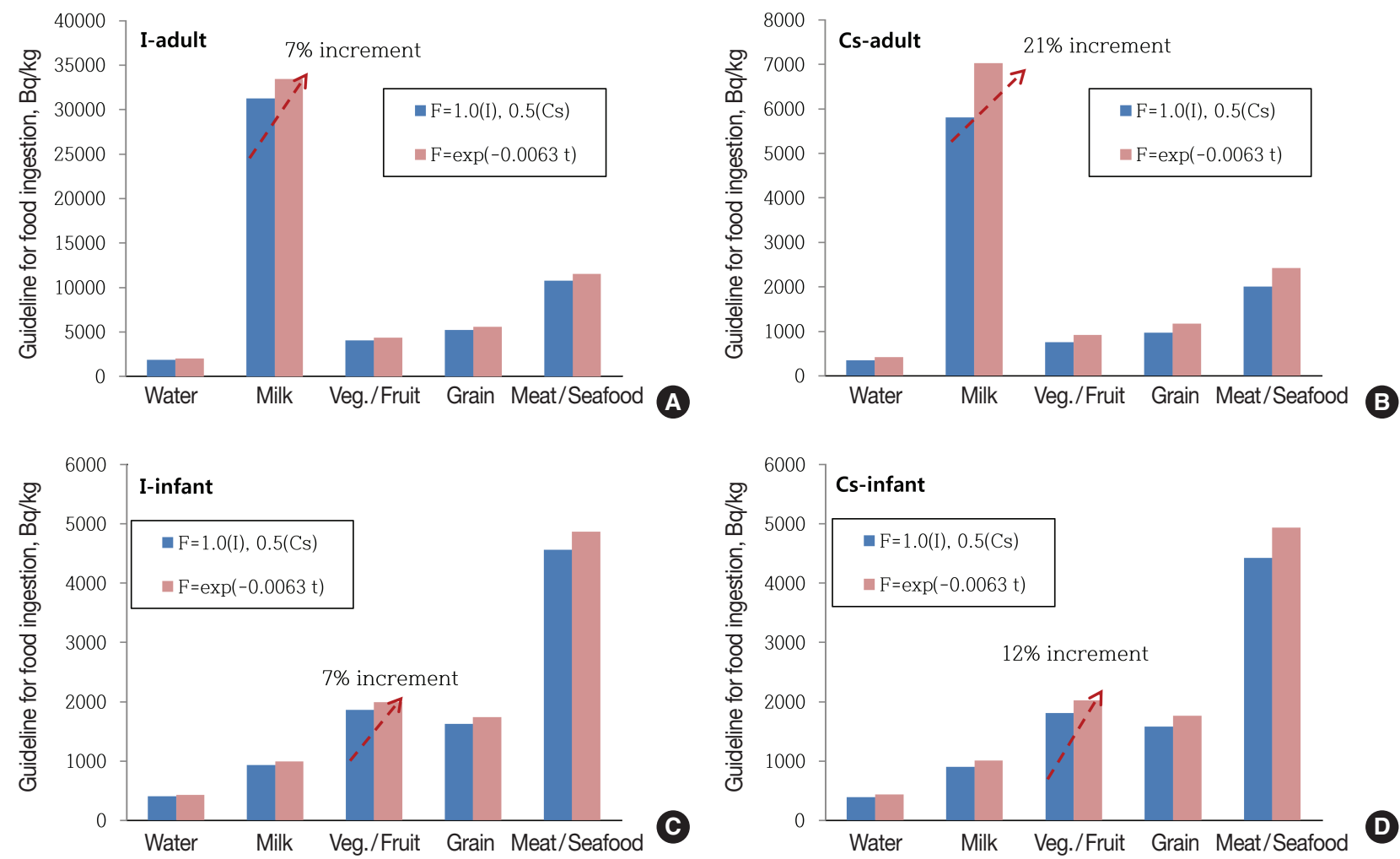

Fig. 1. Effect of market dilution factor of foodstuffs (F) on food guidelines: (A) lodine (adult), (B) Cesium (adult), (C) lodine (infant), and (D) Cesium (infant).
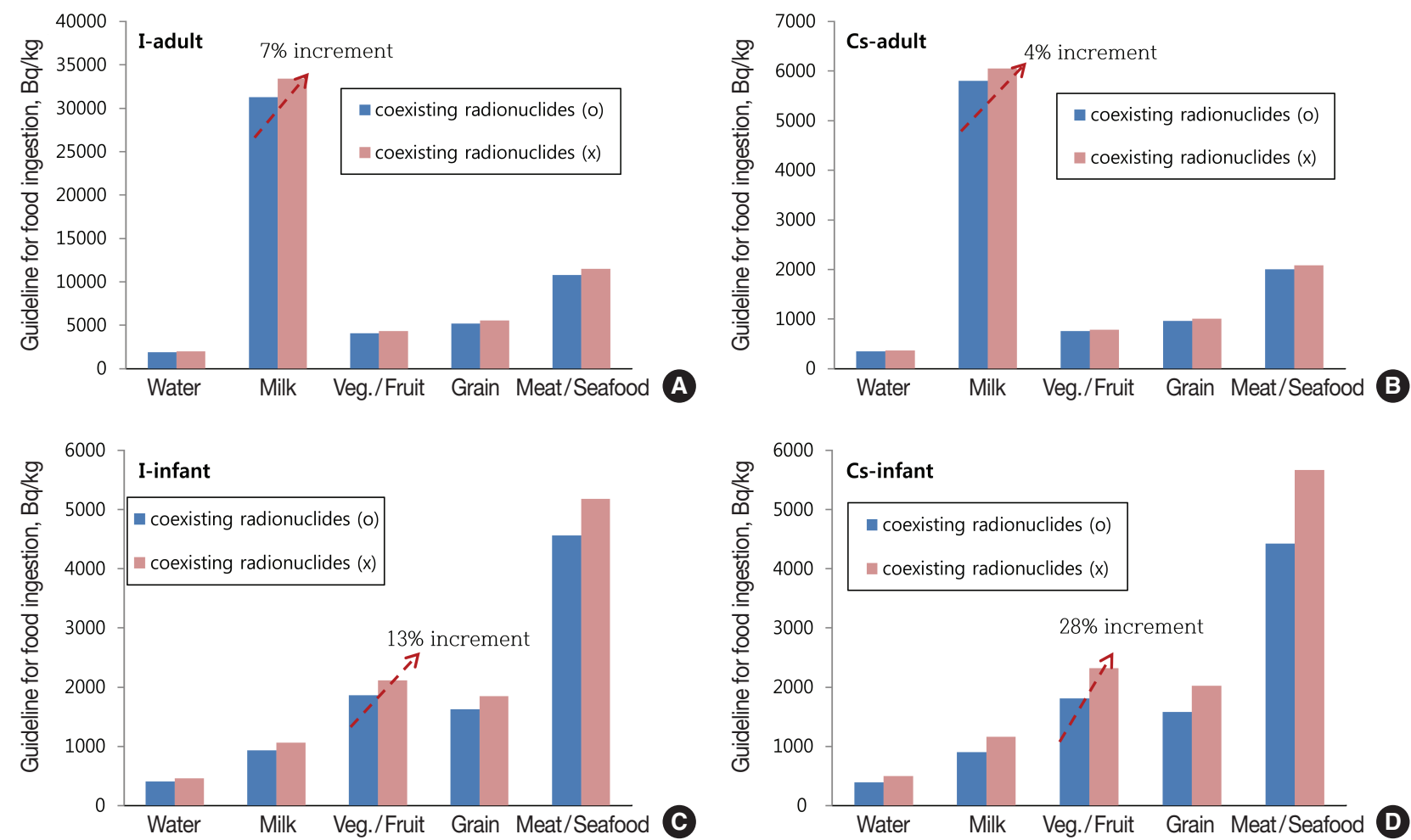

Fig. 2. Effect of coexisting radionuclides on food guidelines: (A) lodine (adult), (B) Cesium (adult), (C) lodine (infant), and (D) Cesium (infant). 


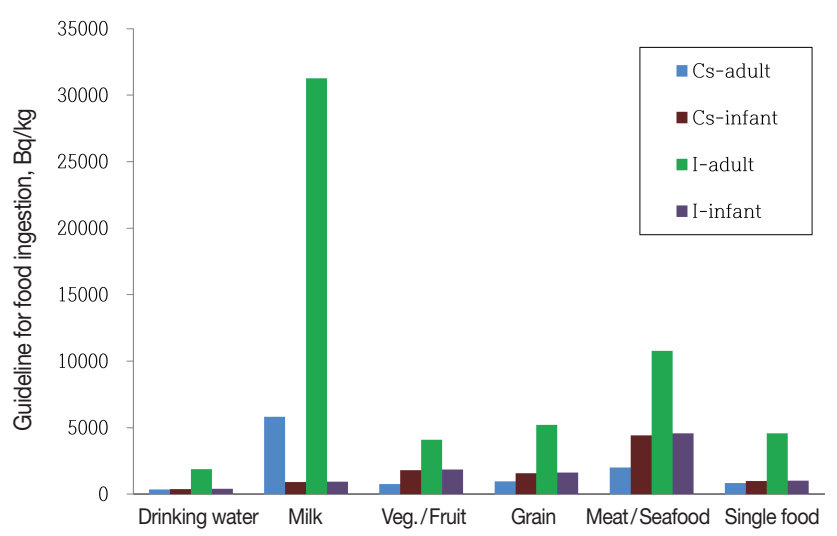

Fig. 3. Comparison of food guidelines between single food and multiple foods.

means that foodstuffs are not classified; that is, the guidelines only apply to the group of radionuclides without any classification of foods. The activity concentration for a single food is conceptually similar to the average value of the derived activity concentrations for multiple foodstuffs. Thus, the derived activity concentration for a single food would be larger than that of a highly-consumed food such as drinking water, but lower than that of a less-consumed food such as meat in guidelines for multiple foods (Figure 3). For instance, in this study, which considered 5 food groups, the index value of radiocesium for drinking water was estimated to be 348 $B q \cdot \mathrm{kg}^{-1}$. The index value for a single food would be 2.4 times greater, at $848 \mathrm{~Bq} \cdot \mathrm{kg}^{-1}$ (Table 3). Guidelines for a single food are obviously simple and easy to use, but can face a certain degree of difficulty when a representative activity concentration is selected from monitoring results of food for implementing protective actions. Additionally, it can bring about excessive protective actions, such as banning the consumption of all foods, even though only small portions of food are highly contaminated.

\section{4) The effect of the intervention level for radioiodine}

This study applied an equivalent dose of $50 \mathrm{mSv}$ to the thyroid ( $10 \mathrm{mSv}$ for each food category) as the intervention level to determine the derived activity concentration of radioiodine. Figure 4 shows the comparison of the derived activity concentration of foods between a thyroid equivalent dose of $10 \mathrm{mSv}$ and an effective dose of $1 \mathrm{mSv}$ as the intervention reference level. The derived concentration levels obtained using an effective dose of $1 \mathrm{mSv}$ for each food type (a total of $5 \mathrm{mSv}$ ) were about twice as large as those derived using the thyroid equivalent dose (a total of $50 \mathrm{mSv}$ ) for both adults

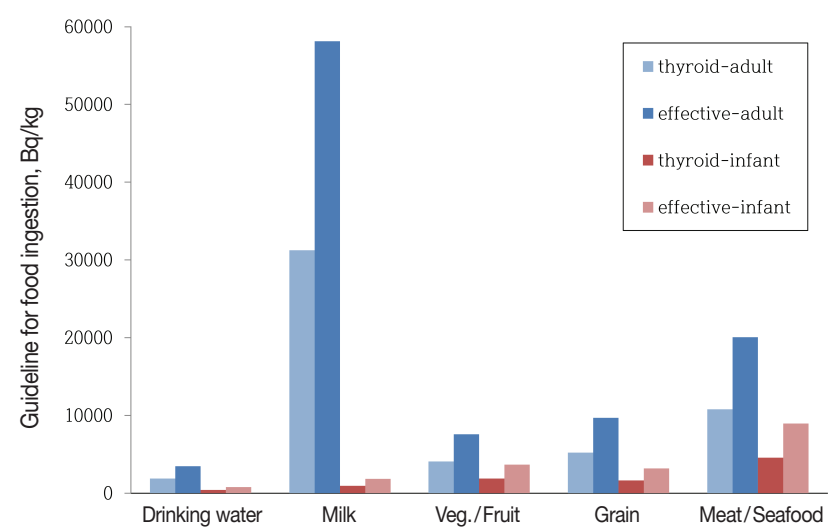

Fig. 4. Comparison of food guidelines for radioactive iodine between the equivalent dose to thyroid and the effective dose for intervention level.

and infants. This result indicates that applying the thyroid equivalent dose as the intervention reference level for radioiodine would result in more conservative results.

\section{Operational intervention levels}

The guidelines for radiocesium and radioiodine are practically convenient in an emergency situation because the monitoring of other radionuclides is not necessary. However, as shown in the previous section, the derived activity concentration for the index radionuclides can vary tremendously according to the values of input parameters, such as the number and ratio of coexisting radionuclides relative to the index radionuclides and the market dilution factor of food. Alternatively, the operational intervention levels (OILs) developed by the IAEA may be used as guidelines for public protective actions if the activities of all radionuclides in food can be evaluated. OILs are suitable for use when responding to an emergency based on the measured radioactivity levels in soil and food.

The derived intervention level to implement public protective actions has generally been determined by model predictions. However, the model prediction often results in a quite different result from the real situation due to uncertainties in the input parameters of the model or in the model itself. Recently, the IAEA recommended that public protective actions should be implemented based on measured activities to the extent possible, based on the lessons learned from the Fukushima accident, which exhibited very different results between model predictions and the measured data for the initial contamination pathway [13]. Therefore, it is desirable to conduct public protective actions using OILs if possible. 
IAEA's default OILs consist of 6 sets of values, OIL1 to OIL6 [4]. The default OIL5 and OIL6 apply to radionuclides in food, milk, or water destined for human consumption that warrant the consideration of restrictions on consumption to keep the effective dose to any person below $10 \mathrm{mSv}$ per annum. The default OIL5 (100 Bq. $\mathrm{kg}^{-1}$ for gross $\beta$ and $5 \mathrm{~Bq} \cdot \mathrm{kg}^{-1}$ for gross $\alpha$ ) serve as a benchmark for initial screening. If the measured radioactivity levels for gross $\beta$ and $\alpha$ of potentially contaminated food are below the default OIL5 values, it would be determined to be safe for consumption; on the contrary, if the measured gross $\beta$ and $\alpha$ radioactivity exceeds the default OIL5, then the radioactivity of radionuclides in food (K) should be measured (Figure 5). If the condition of $\Sigma \frac{K_{i}}{O L_{i}}>1\left(\mathrm{OIL}_{\mathrm{i}}\right.$ is the default OIL6 of radionuclide $\left.i\right)$ is satisfied, the consumption of non-essential food should be restricted. Essential food, milk, and drinking water should be replaced, or residents should be relocated to a different region if alternative food is unavailable. However, when restrictions on food consumption are expected to result in severe malnutrition or dehydration due to the absence of replacement food, the contaminated food may be consumed for a short time until replacements become available. Such an action must be based on a determination that the potential health risks caused by malnutrition would be higher than the risks of radiation exposure by consuming contaminated food.
The IAEA has proposed default OIL6 values for 355 radionuclides. In general, the OIL6 can be calculated by the following equation.

$$
R C I L_{i}=\frac{I L}{W \times C F_{i} \times\left(1-e^{-\lambda_{i} T}\right) / \lambda_{i}}
$$

where $R C I L_{i}$ is the OIL6 value of radionuclide $i . I L$ is the operational intervention level for the regulation of food, and

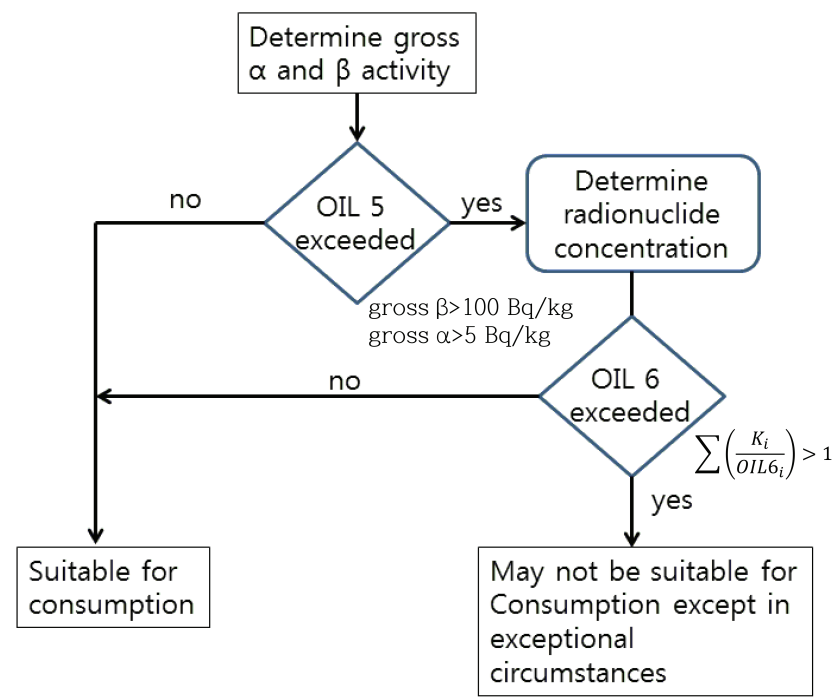

Fig. 5. Process of assessing radionuclide concentrations in food, milk and water [4].

Table 4. The OIL6 Based on the Domestic Food Intake Rate, and Its Comparison with the Default IAEA OIL6 Values

\begin{tabular}{|c|c|c|c|c|}
\hline Radionuclide & Calculated infant OIL6 & Calculated adult OIL6 & Domestic proposed OIL6 & IAEA default OIL6* \\
\hline${ }^{238} \mathrm{Pu}$ & 14 & 113 & 10 & 50 \\
\hline${ }^{239} \mathrm{Pu}$ & 13 & 104 & 10 & 50 \\
\hline${ }^{240} \mathrm{Pu}$ & 13 & 104 & 10 & 50 \\
\hline${ }^{241} \mathrm{Am}$ & 15 & 130 & 10 & 50 \\
\hline${ }^{90} \mathrm{Sr}$ & 620 & 2,435 & 600 & 200 \\
\hline${ }^{106} \mathrm{Ru}$ & 770 & 4,420 & 700 & 600 \\
\hline 129 & 302 & 236 & 300 & NA \\
\hline${ }^{131}$ & 9503 & 37,179 & 9,000 & 3,000 \\
\hline${ }^{235} \mathrm{U}$ & 155 & 553 & 100 & 200 \\
\hline${ }^{35} \mathrm{~S}$ & 81,076 & 387,698 & 80,000 & 10,000 \\
\hline${ }^{60} \mathrm{Co}$ & 1,042 & 7,911 & 1,000 & 800 \\
\hline${ }^{89} \mathrm{Sr}$ & 7,618 & 50,436 & 7,000 & 6,000 \\
\hline${ }^{103} \mathrm{Ru}$ & 26,703 & 124,190 & 20,000 & 30,000 \\
\hline${ }^{134} \mathrm{Cs}$ & 2,462 & 1,611 & 2,000 & 1,000 \\
\hline${ }^{137} \mathrm{Cs}$ & 2,619 & 2,023 & 2,000 & 2,000 \\
\hline${ }^{144} \mathrm{Ce}$ & 1,029 & 6,247 & 1,000 & 800 \\
\hline${ }^{192} \mathrm{Ir}$ & 8965 & 39,806 & 8,000 & 8,000 \\
\hline${ }^{3} \mathrm{H}$ & 861,893 & $1,465,382$ & 800,000 & 200,000 \\
\hline${ }^{14} \mathrm{C}$ & 38,830 & 44,818 & 30,000 & 10,000 \\
\hline${ }^{99} \mathrm{TC}$ & 5,436 & 4,545 & 5,000 & 4,000 \\
\hline
\end{tabular}

*The IAEA (International Atomic Energy Agency) default OIL6 was calculated using the most restrictive age-dependent dose conversion factors and ingestion rates (i.e. those for infants), and the generic criterion of $10 \mathrm{mSv} \cdot \mathrm{y}^{-1}[4]$. 
in this study, an intervention level of $10 \mathrm{mSv} \cdot \mathrm{y}^{-1}$ was applied, as was done by the IAEA. $T$ was set to 365 days to consider the annual ingestion dose. $W$ is the daily food intake rate, and $C F_{i}$ is the dose conversion factor for radionuclide $i$. In the present calculation, the dose conversion factor for 3-month-old infants was used instead of the dose conversion factor for 1-year old infants.

Table 4 summarizes the calculated OIL6 values of infant and adults for domestic food intake rates, in comparison with the IAEA's default OIL6 values. The lowest OIL6 for each age group may be used as the domestic default OIL6. The IAEA default OIL6 values were derived with the agreement of all IAEA members and jointly with the Food and Agriculture Organization of the United Nations, International Labor Organization, Pan-American Health Organization, and the WHO. The IAEA's default OIL6 values for ${ }^{131} \mathrm{I},{ }^{134} \mathrm{Cs}$, and ${ }^{137} \mathrm{Cs}$ are 3,000 $\mathrm{Bq} \cdot \mathrm{kg}^{-1}, 1,000 \mathrm{~Bq} \cdot \mathrm{kg}^{-1}$, and 2,000 Bq. kg ${ }^{-1}$, respectively, and these levels are about 10 times greater than the guidelines for restrictions on food consumption in Japan implemented after the Fukushima accident. This may be explained by the fact that the Japanese authorities strengthened the intervention levels to keep the public ingestion dose below $1 \mathrm{mSv}$ per annum.

The IAEA's default OIL6 values for most radionuclides were lower than those derived in the present study, except for some $\alpha$ radionuclides such as ${ }^{238} \mathrm{Pu}$ and ${ }^{235} \mathrm{U}$. This difference seems to have been caused by the application of the dose conversion coefficient for 3-month-old infants and by the domestic food intake rate. From the perspective of providing conservative guidelines, the present results for $\alpha$ radionuclides and the IAEA's default OIL6 values for other radionuclides are recommended as domestic OIL6 values. However, an in-depth review by experts and stakeholders regarding the logic and input data for calculations is required to develop final guidelines suitable to circumstances in Korea.

\section{Conclusion}

The derived activity concentrations of radiocesium and radioiodine for food regulation in emergency exposure situations were calculated using domestic food consumption rates.

It is suggested that the current APPRE guidelines for radiocesium should be set as conservative levels for infants. For adults, the APPRE guidelines are rather conservative for drinking water and milk, while the guidelines are similar for vegetables, fruits, and grains, compared to the derived activity concentrations of food in the present study. In contrast, the current Korean guidelines for radiocesium are more conservative for all food groups than those of the WHO, except the values for meat/seafood in the APPRE. The index values for radioiodine turned out to be very conservative in both the Korean and global guidelines.

The derived OIL6 values for domestic food intake rates turned out to be greater for most radionuclides than the IAEA's default OIL6 values, except for some a radionuclides.

In summary, the current APPRE and MDFS guidelines for radiocesium and radioiodine are overall conservative, compared to the derived activity concentrations of food based on domestic food intake rates. Combining the IAEA's default OIL6 values with the present OIL6 values for a radionuclides is suggested as a way to generate a new set of OIL6 values for domestic application. However, comprehensive and open discussions among stakeholders, incorporating regulatory authorities, are necessary to rebuild the domestic guidelines on a solid logical basis.

\section{Acknowledgements}

This work was supported by the National Research Foundation of Korea (NRF) grant funded by the Korea government (NRF-2017M2A8A4015252).

\section{References}

1. International Commission on Radiological Protection. Application of the commission's recommendations for the protection of people in emergency exposure situations. ICRP Publication 109. 2009;22-37.

2. International Commission on Radiological Protection. Application of the commission's recommendations to the protection of individuals living in long term contaminated territories after a nuclear accident or a radiation emergency. ICRP Publication 111. 2009;9-14.

3. United Nations Scientific Committee on the Effects of Atomic Radiation. UNSCEAR 2008 reports to the general assembly with scientific annexes, Volume II. Scientific annexes D: Health effects due to radiation from the Chernobyl accident. UNSCEAR 2008 Report. 2011;60-61.

4. International Atomic Energy Agency. Criteria for use in preparedness and response for a nuclear or radiological emergency. IAEA General Safety Guide No. GSG-2. 2011:11-50.

5. Joint FAO/WHO Expert Committee on Food Additives. Codex 
General standard for contaminants and toxins in food and feed. Codex STAN 193. 1995;56-60.

6. Park SH. Safety management of radioactivity in food. The Korean Radiation Protection Association, Summer Workshop. Yesan, Korea. August 23-24, 2012.

7. International Commission on Radiological Protection. Statement from the 1984 Meeting of the ICRP. ICRP Publication 40. 1984;38-39.

8. World Health Organization. Derived intervention levels for radionuclides in foods-guidelines for application after widespread radioactive contamination resulting from a major accident. Geneva, Switzerland. WHO. 1988;17-20.

9. International Commission on Radiological Protection. Principles for intervention for protection of the public in a radiological emergency. ICRP Publication 63. 1992:19-23.

10. Hamada N, Ogino H. Food safety regulations: What we learned from the Fukushima nuclear accident. J. Environ. Radioact. 2012; 111:83-99.

11. Korea Institute of Nuclear Safety. Study for an improvement of INDAC (Integrated Dose Assessment Code Package). Technical Report, KINS/RR-808. 2011;74-78.

12. International Commission on Radiological Protection. Assessing dose of the representative person for the purpose of radiation protection of the public. ICRP Publication 101. 2006:24-26.

13. International Atomic Energy Agency. The Fukushima Daiichi accident, Technical Volume 3: Emergency preparedness and response. STI/PUB/1710. 2015;71-72. 